\section{P-30 LIFE'S QUESTIONS TRAINING MANUALS: HOSPICES, SCHOOLS AND COMMUNITIES TALKING DEATH, LOSS AND GRIEF}

Lisa Patterson. St Nicholas Hospice Care, Bury St Edmunds, UK

\subsection{6/spcare-2021-Hospice.51}

Background Life's Questions (LQ) tested for feasibility, acceptability and appropriateness of the intervention delivery and manual to support a 'train the trainer model' to expand the reach and impact of LQ. Need to spread the skills and expertise of the hospice in a community development programme to include and empower school-aged children in the national strategy to be 'ready, willing and confident to have conversations about living and dying well and to support each other in emotional and practical ways' (Abel, Sallnow, Murray et al., 2016).

Aim The primary aim is to increase scale and reach on a national level with designed, implemented and evaluated branded comprehensive manuals for both the Lead and volunteers extending the LQ project across a national platform. The hospice will act as a hub for resources and delivery support for all Leads in the future.

Method Sixteen new intake of volunteers followed the volunteer manual and three followed the Lead manual to ensure appropriateness of content, style, structure, understanding, efficacy, fidelity and integrity. Planning and working parties with marketing, researcher and deputy head teachers to complete final documentation and resource availability through website password-protected access.

Results Feedback included: 'Great practical session, feel better equipped to engage'; 'Inspiring, interesting'; 'Makes me want to work with the people who attended'.

Conclusion NHS England produced participation guidance to support the Dying Matters coalition in its work to promote public awareness and conversations about dying, death and bereavement (NHS England, 2014). Similarly, The National End of Life Care Partnership Ambitions (2015-2020) recommends that hospices engage in community development programmes, Ambition 6. These manuals ensure sustainability nationally. LQ is in keeping with the NHS comprehensive model of personalised care and involving volunteers in new ways is encouraged in the NHS Long Term Plan by encouraging our communities to take part in conversations with all school-aged children (NHS England - Comprehensive model of personalised care, 2021; NHS long term plan, 2019).

\section{P-31 EFFECTS OF SETTING ON BEREAVED PARENTS' EXPERIENCES OF USING COOLING FACILITIES: A QUALITATIVE STUDY}

${ }^{1}$ Julia Hackett, ${ }^{2}$ Emily Heavey, 'Bryony Beresford. 'Martin House Research Centre, University of York, York, UK; ${ }^{2}$ University of Huddersfield, Huddersfield, UK

\subsection{6/spcare-2021-Hospice.52}

Background UK children's hospices offer parents the opportunity to extend the period with their child after their death by using cooling facilities to slow deterioration. The emergence of portable cooling facilities means that parents have the choice over whether they use these at the hospice or at home. Evidence is needed to support parents to make informed decisions about where to use a cooling facility.
Aim As part of a wider study of bereaved parents' experiences of using cooling facilities, to describe what is supportive, positive and challenging about using cooling facilities in different settings.

Methods Multi-site study involving in-depth interviews with parents bereaved in the previous three years. Data analysis employed narrative and thematic approaches. Eight hospices supported recruitment.

Results Twenty-two mothers and eight fathers were recruited. Twenty families used cooling facilities at a hospice and three in their home. Aspects of the setting offered practical and emotional support or created challenges. Where parents used cooling facilities at a hospice, being in a setting where death was normalised and they could retreat from the public gaze was valued. Staff were empathetic, experienced, spontaneously responded to needs, and provided support to siblings. In contrast approaches to supporting families at home were much lighter touch. For these parents, being together in the family home felt right, and they could provide some normality for siblings. Parents attached symbolic meaning to the setting, some believed their child belonged at home, in a place that their child knew. Others did not want memories of their dead child in their home.

Conclusions Differences in what each setting can offer bereaved parents were evident, however, more evidence is needed to support parental decision-making and enable staff to support parents' choices.

\section{P-32 EXPLORING LOSS AND GRIEF WITH PEOPLE WITH INTELLECTUAL DISABILITIES}

Gemma Allen. The Mary Stevens Hospice, Stourbridge, UK

\subsection{6/spcare-2021-Hospice.53}

Staff working in the intellectual disability sector often experience a lack of confidence speaking with people with intellectual disabilities about death, dying and grief, and attention is required to the training needs of this workforce (Lord, Field, Smith, 2017). A community group that supports people with intellectual disabilities contacted the hospice, expressing concern over individuals who had experienced a recent bereavement. With the support of an art psychotherapist, the hospice facilitated two group creative sessions. The first involved sketching and writing, collectively exploring emotions and feelings relative to grief. One person shared her drawing with the group saying, 'that's how my throat feels when I'm sad. The circles in my tummy are the bubbles I feel when I'm nervous.'

The second involved legacy work and storytelling. This enabled the opportunity to reflect and share stories whilst creating spiritual bead work. Using arts-based approaches and creativity allowed a reflective space for people with intellectual disabilities to explore their feelings of loss and grief. Individuals displayed a varied level of understanding and concept of death, dying and grief and highlighted the importance of using clear and concise language when communicating with people with intellectual disabilities (PCPLD Network, 2020).

People wanted to share their grief with the group, and peer support was significant with people showing empathy, support, and compassion towards one another. Staff felt supported and confident following the sessions, with a greater understanding of loss and grief. 